\title{
Congenital rubella syndrome: ophthalmic manifestations and associated systemic disorders
}

\author{
Kerry T Givens, David A Lee, Thomas Jones, Duane M Ilstrup
}

\begin{abstract}
Congenital rubella syndrome has a wide variety of severe ophthalmic and systemic complications. A worldwide rubella epidemic from 1963 to 1965 affected thousands of infants. This is a 20 year follow up study of patients with congenital rubella syndrome analysing the prevalence of ophthalmic disorders, associated systemic problems, and correlations among these defects. The authors statistically analysed 125 cases of congenital rubella seen in the Mayo clinic ophthalmology department over a 32 year interval. Most patients were young adults. Ocular disease was the most commonly noted disorder (78\%), followed by sensorineural hearing deficits (66\%), psychomotor retardation (62\%), cardiac abnormalities (58\%), and mental retardation (42\%). Multiorgan disease was typical (88\%). Ocular disease and hearing loss were frequently associated ( $53 \%$ had both) but not significantly correlated. A similar association existed between ocular and cardiac disease. Cataracts and microphthalmia were significantly correlated with poor visual acuity (each $\mathrm{p}<0.0001$ ). Glaucoma was significantly correlated with cataracts $(p=0.0002)$ and microphthalmia $(p=0.0024)$ but not poor visual acuity. Four patients with microphthalmia developed late onset glaucoma. No significant association was found between gestational age at time of maternal infection and the incidence of individual ocular conditions. However, several cardiac disorders were significantly associated with gestational age. Although new cases of congenital rubella are rare, surviving victims continue to challenge the ophthalmic and medical communities with a wide range of ocular and systemic disorders.
\end{abstract}

(Br f Ophthalmol 1993; 77: 358-363)

Veale, a Scottish physician, characterised rubella as a benign contagious disease in $1866 . .^{1} \mathrm{~A}$ century later, Sir Norman Gregg described the triad of congenital cataracts, deafness, and heart defects in children of women who had contracted the infection during the first trimester. ${ }^{23}$ The tremendous morbidity associated with the congenital rubella syndrome is now well known to the medical community.

Before perfection of an effective vaccine in 1969 , a worldwide rubella epidemic lasting from 1963 to 1965 affected an estimated $10 \%$ of pregnant women; approximately $30 \%$ of infants from infected mothers ultimately manifested congenital disease. ${ }^{4}$ One recent estimate suggests that, in the United States alone, at least 10000 infants were born with moderate to severe manifestations during that epidemic. ${ }^{5}$ Over the course of the ensuing 20 years, many of those infants have matured into young adults who pose an enormous challenge to the medical community. The complexity and multiplicity of their defects demand the combined disciplines of medicine, special education, and rehabilitation. Because serious ocular abnormalities are commonly associated with congenital rubella, ophthalmologists share the responsibility of managing these patients.

Epidemiological assessment of ocular disease in large populations of congenital rubella patients are few; 17 years have passed since Wolff, following a cohort of victims from the 1963-65 epidemic, published the last indepth report. ${ }^{6}$ Many of the earlier studies employ only descriptive statistics, commenting on apparent associations without actually testing their validity. The subject is worthy of continuing attention, especially because additional ocular disorders associated with congenital rubella have been characterised since Wolff's paper, and because some defects may continue to evolve many years after birth, ${ }^{7-9}$. We reviewed retrospectively 125 congenital rubella cases to discern the prevalence of specific ocular defects, identify associated systemic abnormalities, and discern statistical correlations (if any) among these defects.

\section{Materials and methods}

Charts of all patients with a diagnosis of congenital rubella seen in the Mayo clinic's department of ophthalmology from 1950 to 1982 were reviewed. Criteria for diagnosis of congenital rubella syndrome included classic stigmas (cardiac anomalies, hearing defects, cataracts), plus a history of maternal exposure coupled with rash or positive immunoglobulin $M$ serology and/or isolation of the virus.

Primary demographic data included sex, race, date of birth, date of diagnosis, estimated gestational age at the time of maternal infection, residence (Olmstead County, $M N$, versus all other locations), and the data and patient status at last follow up examination. Records were screened for many clinical variables, tallied in Table 1 (ophthalmic involvement) and Table 2 (involvement of non-ocular systems).

To elucidate correlations among the most prevalent ocular findings (pigmentary retinopathy, cataract, microphthalmia, glaucoma), a battery of statistical tests was applied to the data, examining the coincidence of these conditions with all other ocular findings. In a separate analysis gestational age at time of maternal rubella infection was compared with the incidence of the most common ocular and systemic disorders. All testing was performed using SAS 
Table 1 Manifestations of ocular disease among 125 patients with the congenital rubella syndrome

\begin{tabular}{|c|c|c|c|c|c|c|}
\hline \multirow[b]{2}{*}{ Symptom } & \multicolumn{2}{|c|}{ Unilateral } & \multicolumn{2}{|c|}{ Bilateral } & \multirow{2}{*}{$\begin{array}{l}\text { Total } \\
(\%)\end{array}$} & \multirow{2}{*}{$\begin{array}{l}\text { Others } \\
(\%)^{\star}\end{array}$} \\
\hline & No & $\%$ & No & $\%$ & & \\
\hline Retinopathy & 4 & 3 & 71 & 57 & 60 & $9-61^{1526}$ \\
\hline Cataracts & 13 & 10 & 21 & 17 & 27 & $16-85^{621}$ \\
\hline Strabismus & - & - & 30 & 24 & 24 & $9-60^{21} 24$ \\
\hline Nystagmus & 5 & 4 & 26 & 21 & 25 & $13-38^{615}$ \\
\hline Microphthalmia & 19 & 15 & 10 & 8 & 23 & $10-63^{621}$ \\
\hline Amblyopia & 12 & 10 & 8 & 6 & 16 & $1^{6}$ \\
\hline Glaucoma & 6 & 5 & 5 & 4 & 9 & $2-25^{14}$ \\
\hline Iris coloboma & 4 & 3 & 2 & 2 & 5 & $1^{15}$ \\
\hline Optic atrophy & 2 & 2 & 2 & 2 & 4 & $9^{6}$ \\
\hline Corneal haze & 3 & 2 & 1 & $\bar{l}$ & 3 & $1-8^{615}$ \\
\hline Dacryostenosis & 3 & 2 & - & - & 2 & $4^{15}$ \\
\hline Any eye disease & - & - & - & - & 78 & $30-68^{1214}$ \\
\hline
\end{tabular}

$\star$ Figures published by other authors.

Table 2 Systemic manifestations of congenital rubella

\begin{tabular}{|c|c|c|}
\hline Symptom & No & $\%$ \\
\hline \multicolumn{3}{|l|}{ Otological } \\
\hline Sensorineural defects & 82 & 66 \\
\hline Unilateral & 1 & 1 \\
\hline Bilateral & 81 & 65 \\
\hline \multicolumn{3}{|l|}{ Degree of hearing loss } \\
\hline Mild & 3 & $3 *$ \\
\hline Moderate & 23 & $19^{\star}$ \\
\hline Severe & 55 & 44* \\
\hline \multicolumn{3}{|l|}{ Cardiac } \\
\hline Patent ductus arteriosus & 41 & 33 \\
\hline Pulmonary stenosis & 32 & 26 \\
\hline Ventricular septal defect & 21 & 17 \\
\hline Tetralogy of Fallot & 3 & 2 \\
\hline Coarctation of aorta & 1 & 1 \\
\hline Mitral stenosis & 2 & 2 \\
\hline Atrial septal defect & 6 & 5 \\
\hline \multicolumn{3}{|l|}{ Developmental } \\
\hline \multicolumn{3}{|l|}{ Failure to thrive } \\
\hline Mild & 40 & 32 \\
\hline Moderate & 34 & 27 \\
\hline Severe & 1 & 1 \\
\hline \multicolumn{3}{|l|}{ Psychomotor retardation } \\
\hline Mild & 27 & 22 \\
\hline Moderate & 38 & 30 \\
\hline Severe & 12 & 10 \\
\hline \multicolumn{3}{|l|}{ Mental retardation } \\
\hline Mild & 23 & 18 \\
\hline Moderate & 14 & 11 \\
\hline Severe & 15 & 12 \\
\hline Low birth weight ( $<2500$ grams) & 58 & 46 \\
\hline Prematurity $(<36$ weeks $)$ & 32 & 26 \\
\hline \multicolumn{3}{|l|}{ Neurological } \\
\hline Microcephaly & 53 & 42 \\
\hline Hyperactivity & 22 & 18 \\
\hline Spastic diplegia & 18 & 14 \\
\hline Seizure disorder & 9 & 7 \\
\hline Spastic quadriplegia & 2 & 2 \\
\hline Hydrocephalus & 2 & 2 \\
\hline Hemiparesis & 1 & 1 \\
\hline Other diagnoses & 6 & 5 \\
\hline \multicolumn{3}{|l|}{ Genitourinary } \\
\hline \multicolumn{3}{|l|}{ Inguinal hernia } \\
\hline Unilateral & 7 & 10 \\
\hline Bilateral & 2 & 3 \\
\hline Recurrent urinary tract infections & 7 & 10 \\
\hline \multicolumn{3}{|l|}{ Undescended testes } \\
\hline Unilateral & 14 & 20 \\
\hline Bilateral & 3 & 4 \\
\hline \multicolumn{3}{|l|}{ Hydrocele } \\
\hline Unilateral & 2 & 3 \\
\hline Bilateral & 1 & 1 \\
\hline Hypospadia & 2 & 3 \\
\hline Meatal stenosis & 3 & 4 \\
\hline Hydronephrosis & 1 & 1 \\
\hline Urinary reflux & 2 & 3 \\
\hline Orthopaedic & & \\
\hline Syndactyly & 3 & 4 \\
\hline Scoliosis & 3 & 4 \\
\hline Dislocated hip & 2 & 3 \\
\hline Legg-Perthes disease & 2 & 3 \\
\hline Peroneal palsy & 1 & 1 \\
\hline Calcaneovalgus deformity & 1 & 1 \\
\hline Dental & & \\
\hline Micrognathia & 6 & 9 \\
\hline Hypoplastic teeth & 3 & 4 \\
\hline Cleft lip & 2 & 3 \\
\hline Endocrine & & \\
\hline Diabetes mellitus & 3 & 4 \\
\hline Graves' disease & 2 & 3 \\
\hline Hashimoto's thyroiditis & 2 & 3 \\
\hline
\end{tabular}

*Audiometric data were available for only 103 patients; these percentages reflect that total. software (SAS Institute Inc, SAS Campus Drive, Cary, NC 27513, USA) on a VAX mainframe computer. Analyses included $\chi^{2}$, Wilcoxon two sample, and Fisher's exact tests. Probability values of $p<0.05$ were considered statistically significant.

\section{Results}

One hundred and twenty five patients fulfilled the diagnostic criteria for the congenital rubella syndrome. Sex distribution was approximately equal, with 71 men and 54 women affected (57 and $43 \%$, respectively). One hundred and fourteen patients $(93 \%)$ were still alive at the last date of follow up. All but three of the patients were white; no black patients were among the study population. The median gestational age at the time of maternal infection was 8 weeks (range, 0 to 29 weeks). The majority of patients $(51 \%)$ were born during the worldwide rubella epidemic from 1963 to 1965 (Fig 1).

Age at diagnosis for patients residing in Olmstead County ranged from 0 to 270 days, 45 days being the mean. In contrast, the mean age at diagnosis of all 125 patients was 4.6 years. This delay reflects the high proportion of patients who were tertiary referrals. Only eight of the 125 patients were residents of Olmstead County; of those eight, $50 \%$ had ocular disease, compared with $80 \%$ of the non-residents (difference not statistically significant: $p=0.074$, Fisher exact test; power of test to detect significant difference $=51 \%)$. The mean duration of follow up was 4.5 years with ages ranging from less than 1 year to 65 years (Fig 2 ).

Ocular disorders in the study group are listed in Table 1. Overall, $78 \%$ of the group (97 patients) had some form of ocular disease. The most common finding was pigmentary retinopathy, seen in 75 patients $(60 \%)$ and usually present in both eyes (71 out of 75). Cataracts followed retinopathy in frequency (34 patients or $27 \%$ ). Sixty per cent of the latter group (21 patients) had bilateral involvement. Glaucoma was noted in 11 patients (9\%). No cases of subretinal neovascular membranes, chronic inflammation, progressive cataracts, spontaneous resorption of cataracts, or congenital aphakia were detected.

No significant relationships were detected between pigmentary retinopathy and any other defect, including visual acuity; however, because of limited subgroup sample sizes, the power of our analyses to detect a statistically significant relationship was typically very low for most of the comparisons. For instance, the power to discern a relationship between poor visual acuity (defined as worse than 20/200) for data collected from right and left eyes was only $5 \%$ and $15 \%$, respectively. However, statistically significant associations involving other ocular diseases were identified (Table 3). Notably, the incidence of cataracts in microphthalmic eyes was almost $90 \%(\mathrm{p}<0.0001)$, and both of the latter conditions were significantly correlated with poor visual acuity, regardless of prior ophthalmic surgeries $(p<0.0001)$. Among aphakic patients, acuity ranged from $20 / 70$ to no light perception, mean acuity at last follow up visit being 10/200. 


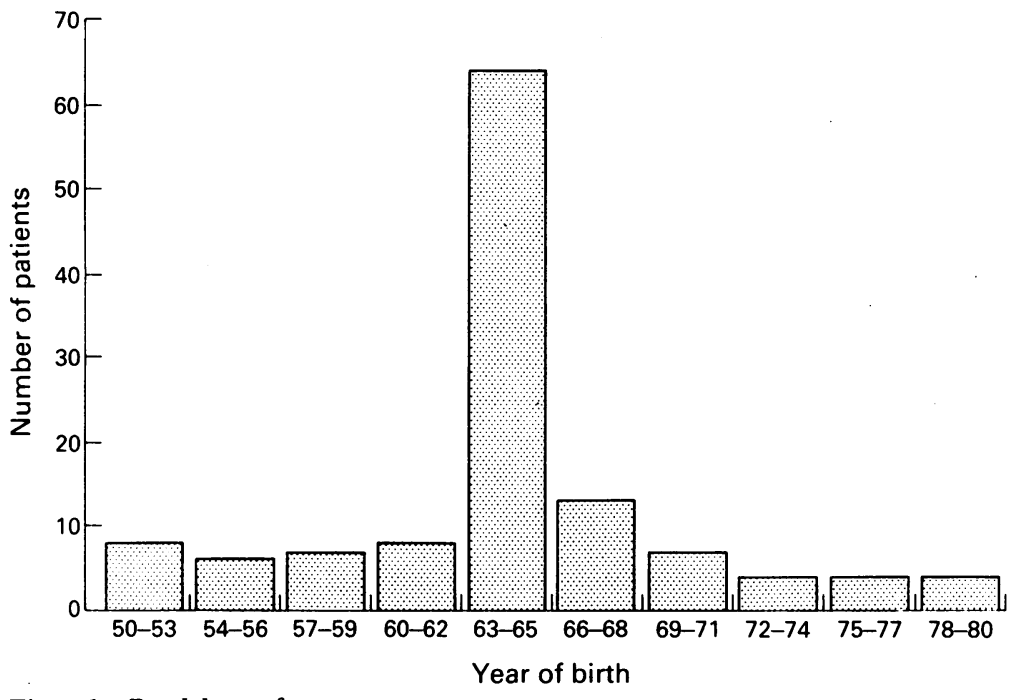

Figure 1 Breakdown of study population by year of birth.

Figure 2 Distribution of the ages of the study population at the time of last follow up visit.

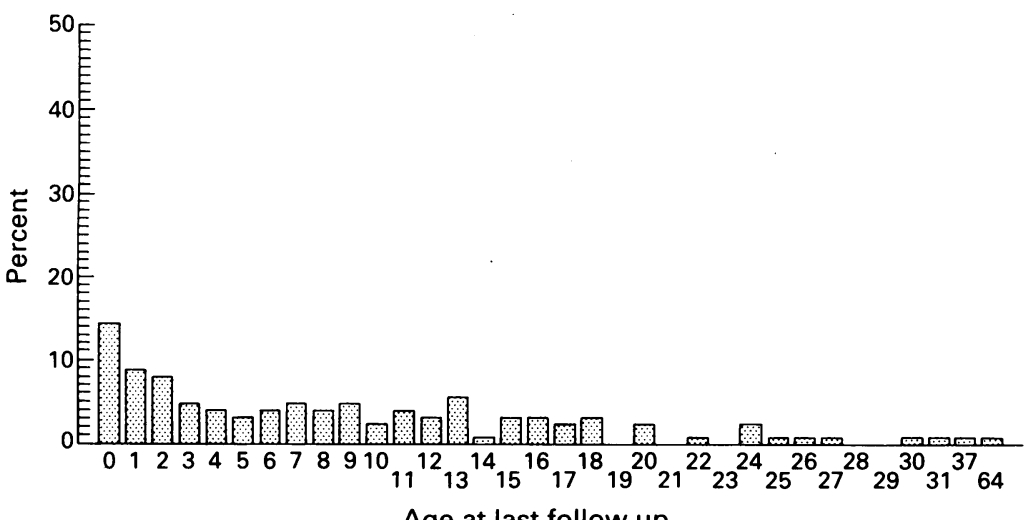
in Table 2. Hearing loss was common in this patient population. Moreover, the prevalence of hearing loss in the entire study group (66\%) was similar to the prevalence of hearing loss in the eye disease subgroup (53\%). Similarly, the occurrence of eye disease in the entire study group $(78 \%)$ was comparable to that among hearingimpaired patients $(80 \%)$. Although the frequent association between ocular disease and hearing deficits was not statistically significant $(p=0 \cdot 28$, $\chi^{2}$ test), the power of the test to detect such a difference was only $18 \%$.

Cardiac defects and ocular disease were also frequently associated in this population (60 patients, or $48 \%$, had both). The prevalence of cardiac disease among patients with eye disease was $62 \%$, compared to $58 \%$ for the entire study group. Conversely, the prevalence of eye disease among patients with heart disease $(82 \%)$ was similar to that for the entire population $(78 \%)$. This relationship was not statistically significant $\left(p=0 \cdot 145, \chi^{2}\right.$ test $)$; the power of the test to detect such a difference was $31 \%$.

The preponderance of defects in the study population occurred in infants exposed to rubella during the first trimester of gestation. While the prevalence of hearing deficits tended to increase with time of maternal rubella infection during the first trimester, the prevalence of ocular and cardiac disease went down (Fig 3); however, only the cardiac trend was statistically significant ( $p=0.009$, Wilcoxon rank sum test); the trend for hearing defects was of borderline significance $(p=0 \cdot 086$, Wilcoxon rank sum test). Although the correlation between gestational age and any single ocular condition was statistically not significant, significant associations were found between gestational age and the following specific cardiac diseases: patent ductus arteriosus, pulmonary stenosis, ventricular septal defect, and failure to thrive (Table 3 ).

A large proportion of the patients demonstrated some degree of developmental or intellectual deficiency. Sixty two per cent of the patients had a history of psychomotor retardation, and $42 \%$ had microcephaly. Table 2 lists the prevalence of other systemic manifestations of congenital rubella, including genitourinary, orthopaedic, dental, and endocrine problems.

Overall, multiorgan disease was the rule: $88 \%$ of the patients suffered involvement of at least two systems, and nearly two thirds (64\%) had abnormalities in four or more systems. Only one patient with the diagnosis of congenital rubella had no detectable defects on last examination.

Age at last follow up

\section{Discussion}

The classic rubella syndrome is characterised by the combination of cardiac, ocular, and hearing defects, although infection and damage can occur in every organ system. As many as two thirds of infants with congenital rubella will be free of any abnormality at birth. Most patients who are symptomatic at birth and many of those who lack signs of infections eventually will have some degree of hearing loss or psychomotor damage. Congenital rubella should be viewed as a chronic infection capable of producing progressive damage. Clinical follow up and testing have shown that ultimately central nervous system damage (hearing loss, intellectual and motor deficiencies) is the most frequent and significant clinical problem associated with congenita rubella. The diagnosis should be suspected when maternal seroconversion or a compatible illness occurs during pregnancy, when a neonate has clinical signs of congenital rubella, and in any infant with hearing loss, retinitis, or encephalopathy of unknown aetiology. Even with a high index of suspicion, many cases will be missed since many mothers and infected newborns also lack clinical signs of rubella. ${ }^{10}$

Both the rate of in utero transmission of rubella and the consequences of fetal infection are related to the stage of gestation at the time of maternal infection. Infection during the first 8 weeks of pregnancy results in a fetal infection rate of about $50 \%$; subsequently, the rate of in utero transmission drops sharply to less than $10 \%$ by the 16 th week. The proportion of 
Table 3 Significant correlations among 125 patients with the congenital rubella syndrome

\begin{tabular}{lllll}
\hline Correlative symptom & $\begin{array}{l}\text { Poor visual } \\
\text { acuity }\end{array}$ & Cataracts & Glaucoma & $\begin{array}{l}\text { Gestational } \\
\text { age }\end{array}$ \\
\hline Cataracts & $\mathrm{p}<0.0001^{\star}$ & - & - & - \\
Microphthalmia & $\mathrm{p}<0.0001^{\star}$ & $\mathrm{p}<0.0001^{\star}$ & $\overline{\mathrm{p}}<0.0024 \dagger$ & - \\
Glaucoma & - & - & - & - \\
Patent ductus arteriosus & - & - & - & $\begin{array}{l}\mathrm{p}<0.0158 \ddagger \\
\text { Pulmonary stenosis }\end{array}$ \\
$\begin{array}{l}\text { Ventricular septal defect } \\
\text { Failure to thrive }\end{array}$ & - & - & - & $\begin{array}{l}\mathrm{p}<0.0299 \ddagger \\
\mathrm{p}<0.419 \ddagger\end{array}$ \\
\hline
\end{tabular}

${ }^{\star} \chi^{1}$ test; $\nmid$ Fisher exact test; $¥ W$ ilcoxon two sample test.

infected fetuses with damage caused by rubella follows a similar pattern. These gestational influences probably are due to a number of factors, including timing in relation to organogenesis, maturation of fetal host mechanisms, and maturation of the placental barrier. Developing fetal organs are damaged by infection of cells in blood vessels in both the placenta and fetus. These vascular lesions are characterised by endothelial necrosis and are often accompanied by petechiae and haemosiderin laden macrophages in fetal organs. In addition, rubella can produce cytolytic infection of host cells; cellular damage caused by virus has been identified in a number of tissues, including myocardium, central nervous system, skeletal muscle, and epithelial cells of the developing inner ear, lens, and teeth. ${ }^{10}$

In the 1960 s and ' 70 s, publications concerning congenital rubella were legion. Since the advent of effective vaccination, the number of new cases of congenital rubella has plummeted and with it the number of reports addressing this devastating disease. Nonetheless, congenital rubella continues to have a sizeable impact on the medical and social community: conservative estimates place society's cost for the long term rehabilitation of patients from the 1963-65 epidemic at \$US1-3 billion. " Because eye disease accounts for much of this burden, congenital rubella merits continued attention from the ophthalmic community.

Most papers from the ophthalmic literature regarding this disease report the incidence and coincidence of various eye findings without test-

Figure 3 Prevalence of selected organ defects relative to gestational age at the time of maternal rubella infection. ing the data statistically. Arguably, in many earlier reports such analysis was problematic, owing to very small samples, uncontrolled variables, and non-random patient populations. While the current study suffers from the usual limitations of a retrospective approach, we none the less feel that prudent application of selected statistics may help clarify important relationships and stimulate directions for further study.

The present study has certain advantages over previous reports: a larger sample size than most, a broader range of patient ages, longer follow up, and more complete assessment of concomitant ocular and systemic variables. On the other hand, our population is heavily skewed towards patients with ocular disease. Because the Mayo clinic is a tertiary referral centre situated in a relatively small city, the majority of patients in this study were probably screened elsewhere and referred specifically because of known eye problems. Not surprisingly, the overall prevalence of ocular disease in this population, $78 \%$, is higher than the $43 \%$ prevalence of eye disease described by Wolff in his prospective review of infants with congenital rubella (of the 11 different eye conditions that W.olff documented in his study, all but two were more frequent among our patients). ${ }^{6}$ Notably, the present study documented a higher overall frequency of ocular disorders, even when compared with other retrospective series (a literature search showed a high of $68 \%) .{ }^{12}$ Longer follow up and larger sample size are probable factors, as both favour discovery of rarer, overlooked, or delayed eye conditions (for example, delayed glaucoma).

Several authors have commented on the frequent association of hearing deficits and ocular disease in congenital rubella patients. Woodruff, in her study of children attending a school for the deaf, noted that $82 \%$ of congenital rubella patients with ocular findings were hearing impaired. ${ }^{13}$ This figure parallels the $80 \%$ prevalence of ocular disease among hearing impaired patients in our study. Some authors have implied that the association between these two defects is non-random. ${ }^{14} \chi^{2}$ analysis of our data suggests the association of these common findings is only coincidental. An alternative explanation is that this test had insufficient power (only 18\%) to uncover a significant relationship, given the limitations of our data. If the ocular and otic systems share some embryological feature resulting in similar vulnerability to rubella dysgenesis, the current evidence remains circumstantial.

Cardiac anomalies are one component of Gregg's archetypal rubella syndrome. Subsequent authors have commented on the specific association between ocular and cardiac defects in these patients. ${ }^{15} 16$ Seltzer et al reported, for instance, that of a population of 100 congenital rubella patients, $95 \%$ of the subgroup with eye disease had associated cardiac defects, compared with only $56 \%$ of the group without eye disease. ${ }^{15}$ Our data show a much lower prevalence of cardiac defects $(62 \%$ in patients with eye findings) and approximately the same frequency of cardiac defects among patients with ocular disorders as among the entire study population. As with the analysis of hearing deficits and ocular disease, however, the power of the $\chi^{2}$ test to 
identify a significant relationship was significantly lessened by sample size.

Several previous studies have described the apparent rarity of combined glaucoma and cataracts in congenital rubella patients, ${ }^{14}{ }^{17-19}$ implying that these conditions are mutually exclusive. Wolff ${ }^{b}$ questioned this conclusion, and with $\chi^{2}$ analysis of prospective patient data showed that the infrequency of the association was due to the overall rarity of glaucoma in all rubella patients, including those with cataracts; glaucoma and cataracts behaved like independent events, and the chance of a patient having both conditions was correspondingly much less than that of having only one. In contrast, our analysis suggests that the two conditions occur together significantly more often than by chance alone. Because glaucoma among congenital rubella patients is not a homogeneous disease, however, such analysis is complicated. The delayed glaucoma following cataract surgery (seen in two of our patients) is felt to have a pathophysiology different from the infantile glaucoma more commonly associated with the rubella syndrome..$^{20}$

Microphthalmia is another variable that may influence rubella related glaucoma. Wolff observed that glaucoma in congenital rubella patients 'may have a special predilection for microphthalmic eyes that have undergone cataract surgery, sometimes years earlier'. In our patient population, microphthalmos was highly correlated with glaucoma, irrespective of previous surgery. Cataracts also showed a very statistically significant relationship with both microphthalmia and glaucoma in our population. While proteins leaking from hypermature cataracts may promote elevated intraocular pressure (for example, as in phacolytic glaucoma), our data do not clarify whether the glaucoma in microphthalmic eyes is secondary to lens mediated effects, angle abnormalities, or both.

The association between microphthalmos and cataracts, though frequent, is not well understood. In our study, almost $90 \%$ of the microphthalmic eyes had cataracts; similarly, O'Neill reported that $100 \%$ of 12 culture proved congenital rubella patients with microphthalmia had cataracts. $^{21}$ In contrast, other researchers have reported microphthalmos as 'usually, but not necessarily' linked with cataract. ${ }^{22}$

Some authors feel that microphthalmos is a non-specific consequence of congenital rubella, a sort of ocular failure to thrive, ${ }^{5}$ perhaps due to the generalised slowing of replication commonly seen in rubella infected cells. ${ }^{23}$ Microphthalmos may, therefore, signify diffuse ocular involvement with virus, although this has not been substantiated in vitro. That an eye with more rubella damaged cells might have several simultaneous defects - that is, glaucoma and cataracts, seems plausible.

While most published reports agree that defects from congenital rubella are more profound and numerous when maternal infection occurs in the first trimester, even third trimester infection may result in significant disease. The literature disagrees, however, as to the exact timing of specific embryological insults. For instance, one author felt the risk of cataract sharply declined after week 5 of gestation, when the embryologic lens capsule was complete ${ }^{17}$; Wolff,' however, wrote that the period of vulnerability extends to week 11 . Cooper and Krugman $^{16}$ felt that hearing deficits resulted primarily from material infection occurring after the eighth week of gestation; Boniuk, ${ }^{24}$ however, attributed hearing deficits to infections preceding the eighth week. Our data did not demonstrate any statistically significant trends between individual ocular diseases and gestational age. Determining precise gestational age at the time of maternal infection is inherently difficult, however, and this factor may have weakened the analysis. Conversely, several cardiac defects demonstrated strong associations with gestational age at time of maternal infection, perhaps reflecting a more sharply defined period of embryonal vulnerability for this organ system.

Delayed ocular disease is an increasingly important consideration in patients with congenital rubella. The characteristic 'salt-andpepper' pigmentary retinopathy shows progressive tendencies in some patients, ${ }^{25}$ although early reports implied the condition was stationary. ${ }^{26}$ Patients with retinopathy may enjoy relatively good visual acuity into adulthood, then experience sudden loss of vision secondary to subretinal neovascularisation. ${ }^{2728}$ Even without identifiable neovascularisation, visual acuity may occasionally reach no more than $20 / 60$ in patients whose only ocular finding is pigmentary retinopathy. ${ }^{5}$ Of 27 patients in our series with isolated retinopathy, one had vision in the 20/100-20/200 range in one eye; interestingly, the vision in the fellow eye was in the $20 / 20$ 20/30 range.

Diabetic retinopathy is considered an increasing threat in congenital rubella patients, since many develop diabetes mellitus with age. Twenty per cent of Gregg's 1941 study cohort had developed clinical diabetes at last follow up; diabetic retinopathy appeared in one patient by the age of 18 months. ${ }^{29}$ Although three patients in the present study had documented diabetes, no diabetic retinopathy was observed.

Like the studies before it, the present review underlines the multiplicity and severity of defects in the congenital rubella syndrome. However uncommon the disease has become, it remains a serious and sometimes treatable threat to vision in thousands of patients.

This paper was presented in part at the annual meeting of the Association for Research in Vision and Ophthalmology, Sarasota May 1990. Supported in part by NIH Grants EY07701 and EY00331, and the Lucille Ellis Simon Glaucoma Research Fund Los Angeles, CA, USA.

1 Veale H. History of an epidemic of Rotheln with observation on its pathology. Edin Med F 1866; 12: 404-14.

2 Gregg NM. Congenital cataract following German measles in the mother. Trans Ophthalmol Soc Aust 1941; 3: 35-46.

3 Gregg NM. Further observations on congenital defects in infants following maternal rubella. Trans Ophthalmol So Aust 1944; 4: 119-25.

4 Krugman S. Rubella symposium. Am f Dis Child 1965; 110

5 Wolff SM. Rubella syndrome. In: Darrell RW, ed. Viral diseases of the eye. Philadelphia: Lea \& Febiger, 1985: 199207.

6 Wolff SM. The ocular manifestations of congenital rubella: prospective study of 328 cases of congenital rubella. prospective study of 328 cases of congenital

7 Frank KE, Purnell EW. Subretinal neovascularization following rubella retinopathy. Am $\mathcal{f}$ Ophthalmol 1978; 86: 462-6.

8 Boger WP III. Late ocular complications in congenital rubella syndrome. Ophthalmology 1980; 87: 1244-52.

9 Sever JL, South MA, Shaver KA. Delayed manifestations of congenital rubella. Rev Infect Dis 1985; 7 (suppl): S164-9. 
10 Berkow R, Fletcher AJ, eds. The Merck manual of diagnosis and therapy. 15th Ed. Rahway, NJ: Merck Sharp \& Dohme Research Laboratories, 1987: 1909.

11 Calvert DR. The rubella epidemic of 1964: problems and response. 7 Am Optom Assoc 1969; 40: 794-8.

12 Harley RD. Discussion comments in: Boniuk V, Boniuk M. The prevalence of phthisis bulbi as a complication of catar surgery in the congenital rubella syndrome. Trans Am Acad Ophthalmol Otol 1970; 74: 360-8.

13 Woodruff ME. Differential effects of the various causes of deafnesss on the eyes, refractive errors, and vision of children. Am F Optom Phys Opt 1986; 63: 668-75.

14 Boniuk M. Glaucoma in the congenital rubella syndrome. Int Ophthalmol Clin 1972; 12: 121-36.

15 Geltzer AI, Guber D, Sears ML. Ocular manifestations of the 1964-1965 rubella epidemic. Am $\mathcal{F}$ Ophthalmol 1967; 63: 1964-1965 rubella epidemic. Am f Ophthalmol 1967; 63:

16 Cooper LZ, Krugman S. Clinical manifestations of postnat and congenital rubella. Arch Ophthalmol 1967; 77: 434-9.

17 Boniuk M, Zimmerman LE. Ocular pathology in the rubella syndrome. Arch Ophthalmol 1967; 77: 455-73.

18 Zimmerman LE. Histopathologic basis for ocular manifestations of congenital rubella syndrome. Am $\mathcal{F}$ Ophthalmol 1968 ; 65: 837-62.
19 Richard JM, Friendly DS. Ocular findings in pediatric systemic disease. Pediatr Clin North Am 1983; 30: $1123 \div 44$ 20 Sears $\mathrm{ML}$. Congenital glaucoma in neonatal rubella. $\mathrm{Br} f$ Ophthalmol 1967; 51: 744-8.

21 O'Neill JF. Strabismus in congenital rubella. Arch Ophthalmol 1967; 77: $450-4$.

22 Alfano JE. Ocular aspects of the maternal rubella syndrome. Trans Am Acad Ophthalmol Otol 1966; 70: 235-66.

23 Rudolph AJ, Desmond MM. Clinical manifestations of the congenital rubella syndrome. Int Ophthalmol Clin 1972. 12: 3-19.

24 Boniuk V. Systemic and ocular manifestations of the rubella syndrome. Int Ophthalmol Clin 1972; 12: 67-76.

25 Collis WJ, Cohen DN. Rubella retinopathy: a progressive disorder. Arch Ophthalmol 1970; 84: 33-5.

26 Krill AE. Retinopathy secondary to rubella. Int Ophthalmol Clin 1972; 12: 89-103.

27 Deutman AF, Grizzard WS. Rubella retinopathy and subretinal neovascularization. Am $\mathcal{f}$ Ophthalmol 1978; 85: 82-7.

28 Slusher MM, Tyler ME. Rubella retinopathy and subretinal neovascularization. Ann Ophthalmol 1982; 14: 292-4.

29 Menser MA, Dods L, Harley JD. A twenty-five year follow-up of congenital rubella. Lancet 1967; ii: 1347-50. 